\title{
Matching Social and Ecological Systems in Complex Ocean Fisheries
}

\author{
James A. Wilson $^{1}$
}

\begin{abstract}
This paper considers ocean fisheries as complex adaptive systems and addresses the question of how human institutions might be best matched to their structure and function. Ocean ecosystems operate at multiple scales, but the management of fisheries tends to be aimed at a single species considered at a single broad scale. The paper argues that this mismatch of ecological and management scale makes it difficult to address the fine-scale aspects of ocean ecosystems, and leads to fishing rights and strategies that tend to erode the underlying structure of populations and the system itself. A successful transition to ecosystem-based management will require institutions better able to economize on the acquisition of feedback about the impact of human activities. This is likely to be achieved by multiscale institutions whose organization mirrors the spatial organization of the ecosystem and whose communications occur through a polycentric network. Better feedback will allow the exploration of fine-scale science and the employment of fine-scale fishing restraints, better adapted to the behavior of fish and habitat. The scale and scope of individual fishing rights also needs to be congruent with the spatial structure of the ecosystem. Place-based rights can be expected to create a longer private planning horizon as well as stronger incentives for the private and public acquisition of system relevant knowledge.
\end{abstract}

Key Words: resource governance; fisheries; complex adaptive systems; scale; fishing effort; decentralization; governance institutions; incentives; multiscale governance; fishing rights; ecosystem management; ecosystem-based management; polycentric networks

\section{INTRODUCTION}

Recently, there has been a parade of scientific articles about how we have overfished the ocean and how, in the process, we have dismantled the structure and functioning of its ecosystems (Pauly et al. 1998, Jackson et al. 2001, Myers and Worm 2003, Frank et al. 2005). This result from fishing appears to be of much longer duration and more serious than had previously been imagined. It clearly points to the need for different ways to manage human activity in the oceans. If there is a consensus forming around this problem, it is reflected in the increasingly strong calls for a shift to ecosystem-based management (e.g., NRC 1999a, $b$, Pew 2003, USCOP 2004, McLeod et al. 2005) and in a growing understanding of the importance of social-ecological linkages (see also, Costanza et al. 1998, Folke et al. 1998, Hughes et al. 2005). How to go about building an understanding of these social-ecological linkages, and then incorporating them into the practical management of ocean ecosystems, is not a matter of consensus.

The strongest analytical traditional that attempts to incorporate human and natural interactions can be found in the single species bioeconomic models that constitute the conceptual basis for most management. This approach is explicit about economic and biological connections, and has been the driver of many of the most obvious management innovations of the last several decades. It is a reasonable attempt to understand human influence on ocean systems, but one has to wonder whether it has disguised the complexity of the ocean in a way that is adaptively dysfunctional. This paper, or essay if one prefers, is driven by a deep skepticism about the fundamental idea that animates conventional bioeconomics, i.e., the presumed ability to control 
biological outcomes at the level of particular populations or stocks. Consequently, this paper explores an alternative perspective, one that conceives of the ocean as a complex adaptive ecosystem. I believe that this kind of exploration is important because, if one begins to look at the ocean in this way, the appropriate restraints on fishing and the institutions that we need for sustainable management appear to be very different from those that appear logical and practical if one holds the conventional bioeconomic view.

For this reason, even though I am a social scientist, the paper begins with a sketch of a mental model of the ocean as a complex biophysical system. The purpose of this sketch is to describe the broad structure and dynamics of this kind of system. The model is used as an alternative to the typical single species, stock-recruitment heuristic. It outlines a way to conceive of orderliness in the natural world without relying upon the concepts of stochastic clockwork mechanisms.

The paper then turns to an analysis of the kinds of fishing strategies that are encouraged when conventional management is applied in a complex environment, the nature of the overfishing problem that results, and why that result is likely to produce, over the long-term, an unintended erosion of ecosystem structure and function. The final section of the paper addresses the question of how we go about designing institutions that will facilitate a sustainable adaptation to ocean ecosystems. The paper frames this question in terms of a problem in the organization of management institutions and the design of individual access rights. The overall point of the paper is that if we hope to make a transition to ecosystem-based management, we will have to begin with reformed institutional arrangements, carefully designed to acquire better feedback about the effect of our actions in the system. Presumably, the scientific and practical knowledge that we gain from the feedback will facilitate our ability to learn and to adapt to the complexity of the ocean.

\section{A MENTAL MODEL OF A COMPLEX FISHERY}

Let me describe, first, the mental model that I think is relevant to, at least, the fisheries of New England and Atlantic Canada, although the knowledge I have of other systems leads me to believe that the broad structure and dynamics of this system are not unique. In the northwest Atlantic, in recent years, a variety of both empirical and historical studies have pointed to the importance of populations' adaptations to a spatially and temporally complex environment and, especially, the extent to which fishing has impaired those adaptations. Ames (1997, 2004) conducted interviews with retired fishermen, for example, that indicate numerous, now extinguished, local populations of cod, haddock, and pollock along the coast of Maine. A variety of other studies draw a similar picture of a heterogeneous and stressed environment, inhabited by locally adapted populations (Frank et al. 1994, Perkins et al. 1997, Sinclair et al. 1997, Taggart et al. 1998, Smedbol and Stephenson 2001, Wroblewski 2001, Green and Wroblewski 2001). The collapse of the great Canadian cod fisheries (Hutchings and Myers 1995), the dramatic changes in species structure in New England (Fogarty and Murawski 1998), and the loss of large predators throughout the region contributes to a picture of a system whose structure has been seriously eroded (Steneck 1997, Jackson et al. 2001, Pauly and Maclean 2003).

The conventional bioeconomic approach to fisheries attempts to simplify this complexity by partitioning the system into multiple, independent, single species components whose long-term dynamics are specified by some version of a stock/ recruitment relationship. The intention is to arrive at a practical understanding of the long-term dynamics of each stock so that we might change our behavior in a way that is consistent with the sustainability of the stock. There is an important and usually unstated assumption that if this is done for all stocks, the broader ecosystem also will be sustained.

However, as John Holland (1998) puts it, there is a hidden order in complex systems that suggests a different way of simplifying. This order is not envisioned as that of a clockwork mechanism with clear and stable causal relationships. Rather, it is conceptualized as a much looser and less predictable order that arises from the constraints generated by the evolved behavior of the biological and human elements of the system. Applied to the marine environment, this perspective begins with the presumption that the species in this, or any, natural environment has coevolved at a relatively broad temporal and spatial scale, and it has coadapted locally and relatively quickly, compared to evolutionary processes, to take advantage of the 
feeding and shelter opportunities and/or to avoid the predation threats of a complex, nonlinear world (Conover 2000, Walters 2000). For example, an opportunity for improved survival and reproduction for herring today because of, say, a fortuitous change in water temperature, becomes an opportunity for improved survival and reproduction for cod or another herring predator tomorrow. These kinds of ecological responses of one species to another, and to changes in the abiotic environment, constrain the abundance of the various populations and, as a result, generate both order and diversity in the system (Levin 1999). It is this system of population regulation, i.e., ecosystem function and structure, that we appear to have eroded through fishing, pollution, and a variety of other interventions.

In this kind of system, regulation of populations is "loose" in the sense that the resulting dynamics are not easily characterized as strongly equilibrating (Hixon et al. 2002). Population responses are often characterized by long delays, exponential growth, and frequent overshoot. It takes a while for the size of one population, say a predator species, to respond to changes in a prey population. As innumerable predator-prey models show, it is extremely difficult, even for two-species models to achieve equilibrium. Chaos and other complicated dynamics are typical; increasing the dimensions of these models simply compounds that apparent disorder (Flake 1998). Complicating the dynamics even more is the overlapping functional role of various species (Steneck 2001); in the language of economics, many species tend to be good substitutes for one another. For this reason, it is difficult to know which species might respond to, say, an explosion of the population of a prey species. The survival of the fish larvae of a predator population, at a particular point in its life history, may depend upon how many, if any, larvae are delivered by currents to, or are retained locally in, a place where at the right time, the right size, and the amount and kind of food has drifted from elsewhere, or has been produced locally. Even though there is a great abundance of prey, the contingencies of this kind of complex, nonlinear environment may result in an explosive, or little or no, response from a particular predator population, or a response that is delayed until early life history conditions are just right. Else, it may mean that another predator is the principal respondent or that the prey species is able to become the predator of the early life history of its erstwhile predator.
The practical question posed by this kind of population regulation is not whether there are forces in the system that constrain the abundance of populations, there obviously are; rather, it is whether those constraints operate with enough force, and in a timely enough fashion, for us to predict the outcome of our interventions in their dynamics. The experience of fisheries population work indicates only a limited capacity to predict our effect upon the near-term size of already recruited population cohorts, e.g., using yield per recruit models, and a near absence of an ability to predict our impact on recruitment (Beverton 1998). In other words, at the population level, what we can measure and control is not necessarily related to sustainability. If we were not in this situation, the calls for ecosystem-based approaches to management would be much less compelling.

Generally, it seems that the conditions in the biophysical system, as opposed to the conditions in the population, tend to dominate recruitment and long-term population outcomes. In a relatively intact system with a fair number of functionally similar species, the range of variations in individual populations, especially those due to changes in recruitment, might be expected to be relatively rapid and irregular, whereas variation at the system level might be expected to be slower and more stable (O’Neill et al. 1986). In systems that have lost various components, or are naturally depauperate, compensating dynamics might be expected to be even looser and likely to lead to highly variable, episodic, and unpredictable changes in the abundance of individual populations (Levin 1999, Holling and Gunderson 2002).

Compounding the difficulty of these dynamics even more, especially from the social/management perspective, is the tendency of these systems to shift to alternative states in which the factors regulating the abundance of individual populations change. These system shifts occur at almost any scale in the system. Relatively fine-scale flips can accumulate to broad systemic effects, and equally, broadscale changes in the biophysical environment due to climate or oceanographic changes or fishing out the top of the food chain (Myers and Worm 2003) can impose dramatic changes throughout the fine-scale components of the system (Steneck 1997, Scheffer et al. 2001, Rietkerk et al. 2004). It would appear that these shifts are more likely to occur in systems with loose regulation, i.e., less response diversity (Elmqvist et al. 2003) and, therefore, less resilience 
to human and naturally occurring change. A particularly worrisome aspect of these kinds of shifts, especially those that occur in response to fishing, is their tendency to drive systems toward degraded states in which a large part of the biological activity becomes concentrated low in the food web (Pauly et al. 1998). As individual elements of the system are lost, system constraints become even looser, and the structure becomes more vulnerable to both internal and external perturbations (Low et al. 2002).

Furthermore, our ability to observe and understand these changes in system structure may be disguised by compensatory shifts among its various populations (Cooper and Mangel 1999, Jackson et al. 2001). That is, the loss of some population components may enhance the growth and abundance of the remaining components and, especially if we observe the system only at a broad scale, we might notice little or no change in spite of significant differences in the underlying spatial structure of the population and system. Nevertheless, the effect on the system is to loosen population regulation still more, increase variability and, thus, the likelihood that populations might be pushed beyond minimum thresholds, or explode into periods of hyperabundance.

Finding a practical way to simplify this complexity means finding ways to monitor and interact with the system so that we get as much feedback about its behavior and our effect upon that behavior as possible. In that regard, the system's physical, i.e., non-living oceanographic attributes, e.g., its topography, currents, chemical make up, and pattern of seasonal change are the most regular elements of the system. These elements are configured in ways that are strongly place based, multiscale, and diverse. Recognizable patterns occur at, say, the scale of the North Atlantic as well as at the scale of a small embayment. One could partition the North Atlantic, or any other large system, into a nested hierarchy of spatially defined, somewhat independent components ranging in size from small estuaries to the North Atlantic as a whole, with each component displaying regularities that strongly reflect its unique oceanographic circumstances (Apollonio 2002).

These regularities, or patterns, allow feedback that makes learning and adaptation possible. The behavior of fish and other organisms, including fishermen, strongly reflects these place-specific abiotic regularities, and their interactions lead to the formation of a spatially structured metacommunity (Guichard et al 2004, Kritzer and Sale 2004). Over any short period, one might observe a hierarchy of communities structured along the lines of the physical system. However, these are open communities in the sense that organisms are not confined, generally, to particular places. Depending upon the particulars of their adaptations, they may move quickly or slowly from one part of the ocean to another, e.g., tunas vs. tunicates. Population components whose genetic make up might be indistinguishable may spawn at separate sites, may be relatively sedentary at a particular location, or may migrate and mix with other components of the larger population. All sorts of complex spatial patterns as well as an equally large number of complex interactions with other species might occur over, say, an annual cycle (e.g., Cowen et al. 2000, Hixon et al. 2002, Robichaud and Rose 2004).

The mobility of an organism causes one's perception of the spatial dimension of ecological connectedness to change according to the temporal scale one adopts. Over a short period, say a matter of days, most organisms are more or less stationary and any small place might be viewed as relatively independent from others; within each locality there is a relatively direct connectedness among organisms. With distance and time, the strength of that connectedness dissipates quickly. Over a period of a season or a year, the mobility of organisms increases and the spatial extent of connectedness enlarges. Over a decade, there is still broader connectedness, but it is less tightly linked and more difficult to observe (O'Neill et al. 1986). Consequently, when one observes the system for periods of short duration, small and generally quickly changing subsystems are the scale at which one might most easily observe coherence, capture feedback, and stand the greatest chance to learn about the system; this is an important attribute that Levin (1999) refers to as "tight local feedback." For longer periods, coherence and feedback appear in larger, slowly changing subsystems, but the ability to capture feedback is hampered by an increasingly large number of intervening events. Thus, what is an open, closed, or leaky system, and what and how well one can observe and understand depends upon the temporal scale that one adopts. For these reasons, explicit recognition of the multiple spatial/ temporal scales of the system is essential if we hope to capture meaningful feedback that allows us to learn and adapt. 
One of the most significant aspects of this perspective, when compared with the conventional mental model, is the sense that order in the system is the result of relatively loose regulatory processes that do not create strong equilibrium tendencies among the populations in the system. This attribute makes human interventions in the system difficult to understand and their outcomes difficult to predict and control. Importantly, it also tends to strongly bias our forecasting ability toward relatively naive extrapolations from current states. Generally, that bias seems related to the mass of the organism, population, or system of interest; the larger the mass, the easier to monitor, and the more likely will be it's continuance in its current state, or rate of change of state, over a given period of time (O'Neill et al. 1986). For example, it is extremely difficult to successfully forecast the abundance of cohorts of larval and juvenile fish, whereas it is much easier to forecast changes in the abundance of already recruited cohorts of mature fish. This bias has important implications for the way in which we organize our observation of the system, for our sense of the kinds of biological outcomes we can control or influence, and especially for our understanding of the regulatory response of fishermen to different kinds of rights.

\section{CONVENTIONAL MANAGEMENT IN A COMPLEX ENVIRONMENT}

These ideas about the complexity of ecosystem structure and function are more or less in the mainstream of ecological science, but it has been difficult to incorporate them into applied fisheries science and management (Hutchings 2000, Degnbol 2001, Hughes et al. 2005). As a practical matter, in spite of our knowledge about the complexity of these systems, if not the details of that complexity, we act as if the long-term dynamics of individual populations are regulated mostly by their own numbers. I think it is fair to say that we do this because, given our limited ability to monitor the resource and forecast the results of our actions, it appears to be a useful and practical way to act.

However, if one views the oceans as having complex spatial and temporal dynamics such as outlined in the mental model above, and certainly if one considers the current state of the marine environment, it is reasonable to be skeptical about the viability of this approach. One might identify three aspects of conventional management that, together, are the source of this skepticism. The first concerns the effectiveness of management based on the idea that we are able to affect the sustainability of a stock through controls on fishing mortality. This idea is the foundation of almost all thinking about the design of management institutions and, especially, of access rights appropriate for longterm sustainability. However, it is not an approach that managers have found easy to implement, because the long chain of nonlinear events between spawning and eventual recruitment makes prediction extremely difficult. Consequently, management usually directs its attention to the yield of larger, already recruited fish, because doing so is consistent with our limited abilities to forecast changes in short-term abundance, not because it is necessarily related to long-term sustainability (Beverton 1998).

Second, the mental model described above and the evidence of the complex spatial behavior of fish stocks are reason to be skeptical of the ability, using conventional management approaches, to match or assign fishing effort to individual stocks and, therefore, to know what stocks are actually being fished. In other words, even if we were able to forecast the effect of fishing effort on recruitment, the inability to know the stocks that are being fished calls in to question the practical, regulatory result of proceeding as if we could do this. The third area of skepticism concerns the ability to treat the system as if it were decomposable into independent speciesspecific units. This presumed ability carries with it strong and naively optimistic assumptions about the ways in which human interventions accumulate in the system as a whole. There seems to be little reason to expect species-specific, short-term "optimal" harvesting strategies to add up to a system result that is desirable. These three problems, i.e., recruitment, spatial complexity, and the cumulative effects of our actions are hard to separate. In the section that follows I emphasize problems of spatial complexity, because they tend to bring together all three concerns.

\section{Problems of spatial complexity}

It is generally accepted that building robust and effective institutions for the management of resources requires a close match between the spatial extent of the resource and the institutions used to manage the use of that resource (Ostrom 1990, Folke et al. 1998, Young 2002). Mismatches tend to create 
serious impediments to conservation that are especially obvious when the range of the fish is broad enough that they cross national political boundaries. However, much less attention is paid to the kinds of mismatches that disguise fine-scale and more complex adaptations of fish populations.

Suppose, for example, that managers are dealing with a population of a single species that ranges over a large area. Assume that managers proceed as if that species might be separated from the rest of the ecosystem and as if its abundance could be sustained principally through the appropriate choice of a harvest rate that maximized the yield of fish already, or about to be, recruited to the population. To complicate the usual biological assumptions just slightly, suppose that this is a metapopulation whose components are spatially separated stocks that have adapted through behavioral or genetic means to local circumstances.

If managers were not aware of these spatially separate components, or if they were and, because of administrative costs or other constraints, proceeded as if they were dealing with a single, homogeneous group, assessments and other estimates of the status of this metapopulation would reflect an average of its components. Such a number might be a reasonable estimate of the total numbers in the metapopulation, and they might lead to a reasonable estimate of the rate of fishing mortality necessary to maximize average yield per recruit over the entire metapopulation (Cooper and Mangel 1999). However, those measurements would effectively disguise the fine-scale structure and long-term dynamics of the populations' local components. Most importantly, any estimate of allowable fishing mortality for the metapopulation as a whole would ignore the fact that rational fishermen would selectively concentrate their effort on those localized population components that were most abundant at any one time (Wilson 2002, Wilson et al. 2000). In other words, unlike managers, fishermen would pay close attention to the heterogeneous spatial aspects of the metapopulation and would not fish "on the average." As each local population bloomed, the preponderance of fishing effort would shift to take advantage of the catch-rate efficiencies that each bloom produced.

Under these circumstances, the potential level of fishing mortality that could be applied to each component would be the amount managers had calculated for the entire metapopulation and, in every instance, the potential level of effort would be in excess of what was appropriate for any of the local components of the population. The result for each component would be de facto open access, even with strict, i.e., precautionary, metapopulationlevel controls on fishing mortality. Each fisherman would strive to find the most abundant, or profitable, local component, to fish it as efficiently as possible and then, as the catch rate fell, and taking into account the probable costs of search, leave to find the next most, now first most, abundant, or profitable local component. For fishermen, successful competition in this kind of regulatory regime requires adaptations that usually emphasize large, mobile technology that is able to efficiently locate and harvest fish aggregations over the broad range of management, which is not the range of the stocks. Mancur Olson (2000) compares these kinds of incentives to those of a "roving bandit." Olson's phrase is colorful but in this situation the behavior is fully legal and fostered by the scale of the fishing rules created by managers. For the fisherman in this situation, competitive pressures mean they must always think of the next place to fish; any thoughts of stewardship that they might harbor about the current location of fishing is clearly inconsistent with self-interest, simply because the individual benefits from voluntary restraint at a fine scale cannot be captured in a broadscale management regime.

Of course, if managers realized they were faced with a spatially simple metapopulation like this, they might be in a position to draw appropriate boundaries that would allow them to match fishing mortality with the growth capabilities of each component. Then, the problem of loss of population components might be more easily addressed. However, it would seem more likely that a metapopulation of fish in any kind of complex system would not separate itself into spatially distinct components throughout its life cycle. Consider, therefore, a slightly more complicated biology in which a metapopulation is characterized by components that are segregated at certain times of the year and/or during particular life stages and mixed at others, e.g., separated when spawning and mixed on the feeding grounds. Salmon would seem to be the archetypical example of this kind of population structure.

With this kind of spatial-temporal pattern, even if managers knew about or suspected a metapopulation 
structure, there would be little that they could do to match effort to each component unless the fishery took place at a time in the life cycle of the fish during which the components were separated. For example, the Canadian fishery for roe herring (Clupea harengus) in the Bay of Fundy takes place on the spawning grounds and appears to conform to these circumstances (Stephenson 1998). However, when a fishery takes place at times when the components of the population mix, the outcome would depend upon the fine-scale interactions of fish and fishermen. If the components of the metapopulation were randomly mixed in space, an economically efficient search would lead to effort applied in proportion to the abundance of each component. If the fish were segregated into aggregations or schools associated with each population component, fishing effort might be directed more than proportionately onto the denser aggregations and, depending on the fine-scale interactions of fish and fishermen, could threaten the long-term integrity of those components. Other more complicated and changing patterns of mixing and separation might be possible and plausible from an ecological perspective. Furthermore, patterns of mixing might be expected to change from year to year or season to season as the abundance of the various population components, the behavior of the fish, and the other biophysical attributes of the system change. Each pattern of mixing is likely to lead to unique and, given broadscale assessments of the population, undetectable impacts on the structure of the metapopulation (Cooper and Mangel 1999).

This kind of spatially complex behavior might appear to make broadscale management fatally flawed, but this is not necessarily correct. In this, and in the spatially simple case, fishermens' tendencies to switch among fish stocks and fish populations' and tendencies for compensating growth would effectively mitigate management's impairment (Wilson and Townsend 1986). One might view the result as stumbling from one to another episode of local component overfishing, while always being forgiven by a resilient system. However, if fishing tended to push population components across a threshold beyond which successful reproduction was threatened, even if only occasionally, and if the effect of crossing that threshold was relatively long-term as seems to be the case (Jackson et al. 2001, Ames 2004, Frank et al. 2005), then one would expect broadscale management to lead, over the long term, to the erosion of the spatial structure of the population, in spite of restrictive controls on fishing mortality at the level of the metapopulation.

The great difficulty this poses for management is that the factors that determine population thresholds are not easy to understand and are likely to be the result of fine-scale events that are hard to monitor. At any time, the minimum viable size for a population component is undoubtedly the result of many factors. An unusual combination of otherwise common events might make a population unusually sensitive, or unusually resilient, to fishing. For example, a storm followed by a sudden drop in temperature, accompanied by the inward migration of a large population of predators might push a local prey population into a restricted area and create great fishing conditions in which fishermen's catch rate stayed high until the population was pushed below a size necessary for successful reproduction.

Furthermore, as the number of evolved elements in the biological system declines over time due to fishing, the compensating responses that both restrain and enhance populations are weakened. This increases population variability and the likelihood that any individual component in the system might explode into hyperabundance or be pushed beyond its minimum viable level and lost. Modern fishing techniques compound the problem. Efficient search and catching technologies allow boats to continue fishing small patches when they might otherwise tend to leave to search for ones with greater density. With each local loss the constraints that create order in the system loosen still further, resilience declines even more, and the likelihood of further loss of constraining structure increases, leading to a cascade toward a different and usually degraded alternative system state (Pauly et al. 1998, Rietkerk et al. 2004). This kind of outcome is qualitatively different and a much more serious form of overfishing than that contemplated by the conventional perspective.

\section{Some fine-scale examples}

The long-term effect of fishing on ecological structure and function is the accumulated result of a large, or sometimes small, number of discrete, fine-scale events. Three examples from Maine will suffice to describe these effects, but almost any fishery in the world would probably yield a similar history. First, until the advent of trawlers, cod (Gadus morhua), the dominant predator in the 
system, were taken mostly with hook and line. Because cod do not tend to feed when they are part of a spawning aggregation, the use of hook and line technology creates a virtual sanctuary for the fish during their spawning period. Unfortunately for the cod, they tend to gather into dense schools in preparation for and during spawning. For a trawler, this behavior creates the ultimate target. Interviews with retired fishermen who brought this technology to the coast of Maine during the 1930s and 1940s, speak of huge hauls of ripe and running cod from a number of localized, relatively small spawning areas (Ames 1997, 2004). Many of these apparently discrete spawning components were extirpated in the first 20-30 yr of trawling, and have not been reestablished in the 60-70 yr since.

A similar experience appears to have occurred with the herring fishery. Until the 1970s along the Maine coast herring (Clupea harengus) were caught almost exclusively with passive gear, e.g., weirs and stopseines. The location of this gear was strictly limited by the occurrence of favorable shore, bottom configurations, and the behavior of the fish. Searching out the fish was not possible. Conducted in this way, the fishery persisted at a relatively high harvest level for over $100 \mathrm{yr}$. With the advent of electronic fish finders, large purse seines, and midwater trawls, fishermen acquired a greatly enhanced ability to chase down and extinguish individual schools. Coincidentally, the presence of fish in coastal waters has gone into a sharp decline. The inshore, passive gear fishery disappeared in the early 1980 s, except for a few operations in the fareastern part of the state (Graham 1982, Neal 2001).

At the same time, National Marine Fisheries Service assessments of herring populations in the entire Gulf of Maine and on Georges Bank indicate a relatively abundant metapopulation. Nevertheless, even though the abundance of the metapopulation may not have declined, there has been a significant shift in the spatial distribution of the components of that population. This could be passed off as simply a change in the habits of the fish, or it could signal a substantial loss of many components of the population, accompanied by compensating growth of those that remain. It is, of course, arguable whether this new technology was responsible for the loss of the inshore components of the population. Nevertheless, the timing of its introduction and its scale are entirely consistent with that possibility.
The green sea urchin (Strongylocentrotus droebachiensis) fishery in Maine provides another sobering example of our inability to match the characteristics of fishing effort with the behavior of natural populations. This fishery is an inshore fishery pursued by divers and by small boats using lightweight trawls. It was initiated in Maine about 1986, reached peak landings in the early 1990s, and by 2000 had virtually disappeared. Reproduction is by broadcast spawning and requires sufficient local densities for success. Once the larvae settle, urchins are sedentary. The population tends to aggregate in patches associated with ledges, reefs, and other physical features that provide favorable conditions for feeding, survival, and spawning (Steneck et al. 2004). Fishermen, of course, are attracted to these local patches. In the early years of the fishery, effort concentrated on the more abundant and easily accessible patches. As these patches were fished down, fishing shifted to the less abundant and less accessible patches. In the fished-down patches, kelp began to grow and dominate. New populations of micropredators then developed in the kelp and prevented the further recruitment of urchins (Varinec 2003), effectively protecting the kelp from urchin herbivory and creating, thereby, a local system shift. This process proceeded, generally, from west to east along the coast. For all practical purposes, the metapopulation of urchins was fished out piece-by-piece, and these local system shifts accumulated to the near complete loss of the fishery. Viewed from a broad scale, one would have observed a classic boom and bust cycle of overfishing. Viewed from a finer scale, one would have observed the successive "winking-out" of hundreds of local patches, contributing to the loss of the entire fishery (Jones 2005).

The common element in these three examples is that the interaction of fish behavior and fishing gear at a fine scale appears to have led to the extirpation of local aggregations of these organisms. If those aggregations were simply ephemeral patches of a larger population, little long-term damage might have been expected. However, those extirpations appear to have had long-term ecological effects and, consequently, it would be reasonable to conclude that their accumulated impact has had a significant detrimental effect, not only on the populations directly, but on the system as a whole. 


\section{Mismatches in a complex fishery}

Our scientific conception of ocean systems is the filter that determines our perception of the ways in which human behavior affects those systems. The mental model outlined above generates a perspective that suggests two different forms of overfishing. One is more or less consistent with the conventional perspective. It occurs in the context of a relatively resilient ecosystem in which blunt controls on fishing mortality are not well-matched to individual stocks. The mismatch is manifest in the roving bandit incentives that encourage grab and run, rather than stewardship behavior at any scale below the scale of management. In spite of these unintended effects and as long as each population component remains reproductively viable, conventional broadscale controls over mortality can be expected to work, more or less, because the adaptive responses of both the fishermen and the fish can be expected to compensate for management's inability to match effort with population components.

The great danger of broadscale conventional controls is that they tend to generate strong incentives for efficient fishing strategies and technologies that operate at a fine scale, i.e., finer than the scale of management rules, and they tend to increase the chances that the individual elements of ecosystem structure will be occasionally extirpated, i.e., population components, habitat, etc. This is the second form of overfishing, what might be termed ecological overfishing. The loss of individual system components that marks ecological overfishing tends to be long lasting, erodes the underlying structure of the ecosystem, and, as these losses accumulate, increases the likelihood that the system, at whatever scale, might flip to a generally degraded alternative state. This perspective on overfishing strongly suggests the need to move away from an emphasis on broadscale controls on fishing outputs, i.e., fishing mortality, and toward input restraints that are easier to adapt to and more likely to protect the fine-scale behavioral traits of individual fish and populations. The overall objective has to be the maintenance of ecosystem structure and process (Hutchings 2000, Pitcher 2001). Part of the argument below is that a change in management objectives coupled with a change in governance will allow us to use input controls to more effectively match human behavior to ecosystems. In a slightly different light, this perspective recasts the management problem from one that attempts to predict, manipulate, and optimize numerical targets for individual populations into one that aims, instead, to maintain the circumstances of a healthy system, i.e., does not attempt to produce particular, especially stock level, outcomes.

\section{MANAGEMENT FEEDBACK IN A COMPLEX ENVIRONMENT}

This change in the objective of management, i.e., toward the maintenance of ecosystem structure, implies a relatively substantial collective learning problem (Friedmann 1987, Gunderson 1999, Folke et al. 1998). This section of the paper does not address that learning problem directly. What it asks instead is a more limited question: how might we design our management institutions and the fishing rights of individuals so that, together, they generate as much public feedback as possible about the effect of our actions in these systems? Presumably, our ability to learn and adapt is critically dependent upon our ability to obtain feedback about the results of our action. The argument is that the circumstances determining that ability are principally a function of how well we match the organization of our management institutions and the terms of individual access, to the spatial, temporal, and behavioral dimensions of the environment, what Ostrom calls congruence (1990). However, congruency is costly. As we try to create a closer fit between the organizational hierarchies of human and natural systems, we create more boundaries, more enforcement, and higher coordination costs. To the extent that we can achieve a reasonable trade-off between the benefits of better fit and the costs of that fit, we relax the practical resource constraints that limit the kind of science and management that we can do. Thus, appropriate organization makes it easier for us to acquire and apply useable knowledge of the natural world. Similarly, well-matched rights create circumstances in which individuals have a self-interested incentive to act and acquire knowledge that is consistent with the solution of our collective problem of adaptation. Together, organizations and rights that are well-matched to the system are a necessary foundation, but not a guarantee, of effective governance. 


\section{Transaction costs and multiscale governance}

Fisheries management is costly. We have to expend resources, decide what data we need about the environment, acquire that data, analyze it, discuss its uses, make decisions, implement them, and most importantly, learn from this entire process so that we better understand the effect of our actions on the system. The costs are usually substantial and force us to place limits on the information and knowledge that we can acquire and what policies we can apply to a complex system.

The organizational principles that apply for adaptive and efficient fisheries management, i.e., a management process that can be improved over time, are the same as those that apply to the organization of any large, and almost all small, enterprises whether they are governments, corporations, or cooperatives. For any organization, the greater the heterogeneity, and the more rapid the change in its environment, the greater are its information requirements for successful adaptation. The costs of acquiring and using that information are determined largely by the structure of the organization, i.e., whether it is relatively centralized or multiscale, i.e., decentralized, and the way that structure is matched or mismatched with its environment.

If we imagine we are in a stable, simple environment, an organization designed for centralized decision making appears eminently rational. Managers face low transactions costs. Because feedback is regular and contains little noise, the knowledge they acquire accumulates, and ages only slowly. Under these circumstances they can, even through trial and error, figure out an optimal collective outcome and devise rules to make sure that that kind of outcome occurs. However, in a complex environment, our sense of rational decision making changes in significantly important ways. For example, Frederick Hayek (1945) makes the point that centralized decision makers cannot deal with the diversity of complex economic systems, because they know so little about local conditions. Their ignorance is not necessarily ignorance of scientific principles or of rigorous analytical procedures; it is ignorance of local conditions engendered by the high, unsupportable costs of monitoring, analysis, decision making, and the ability to react within a time frame appropriate to local conditions. The problem he points to is one that arises in complex systems in which the particulars of time and place are important to system outcomes. These particulars place significant limits on decision maker's ability to act with full rationality and often render the results of wellintentioned, centralized decision making ineffective, replete with unintended and, ultimately, irrational consequences (Scott 1998).

These same general ideas flow out of the new institutionalist contributions to organization theory (e.g., Arrow 1974, Williamson 1985, Simon 1996). A corporation, or any other large organization, is faced with significant costs associated with acquiring knowledge of its environment and operations. These costs force the organization to confront two fundamental trade-offs between: (1) centralized and multiscale control of the production of goods and services within its own organizational framework, and (2) production within its own organizational framework and the purchase or acquisition of those same goods and services on the market or through government. Most of the significant innovations in industrial organization are changes that economize transactions costs and, thereby, make new ways to organize production feasible. An assembly line, for example, with its continuous repetition of the same tasks using the same materials to produce the same output is intended to standardize activities at the local level so that central managers can efficiently coordinate production. However, as anyone who has ever worked in a factory knows, even in these deliberately simplified circumstances, the particulars of time and place rear their ugly heads, and efficient production requires the devolution of considerable discretionary authority to the line foreman and even to individual line workers.

As the local environment of an organization becomes more diverse and changeable, the transactions costs of centralized organization rise. If managers attempt to maintain centralized control under these circumstances, they find that large sets of potential policies are infeasible, because information acquisition and implementation are too costly. For example, in fisheries numerical catch controls, closed areas and gear restrictions are policy options that are generally feasible, even if imperfectly, at a broad scale. However, policies that are designed to respond to timely information about fine-scale fish movements and behavior, habitat conditions, and other sorts of fine-scale ecological attributes of organisms and populations, especially those subject to rapid change, are not usually 
practical, because the transactions costs of monitoring, analyzing, and deciding at this scale tend to be so substantial when they are undertaken by a centralized authority.

In fisheries, multiscale management can ameliorate these problems, but only when the structure of the managed system imparts some independence to local subsystems, a property that Simon (1996) calls near-decomposability. Near-decomposability means that some events at the local, or subsystem, level have impacts and feedback that are retained within that locality (Frenken et al. 1999, Levin 1999). In the absence of some local independence, everything is connected to everything else and hopelessly complex. The mental model outlined earlier argues that the relative independence of subsystems, as defined by the regularities of physical and oceanographic features, provides a consistent way of simplifying ecosystem complexity. Coves, bays, coastal shelves, basins, and broad oceanographic regimes collocate with days, lunar cycles, seasons, and decadal shifts (Apollonio 2002) to create a set of boundaries, i.e., discontinuities that partition the complexity of the system into a nested spatial/ temporal hierarchy of almost independent subsystems.

In principal, the number of levels in that nested hierarchy might be extremely large, however, as a practical management matter, its depth is a matter of economics. The desirable extent of nesting, or the number of levels in the hierarchy, depends upon the trade-off between the benefits of the better feedback that can be obtained at local levels and the higher costs associated with the maintenance of more boundaries. The latter can be expected to rise exponentially with the creation of more levels, thereby, limiting the practical amount of organizational devolution that might work. Nevertheless, given the generally broad scale of current management, efforts to create incrementally smaller-scale management units are not likely to encounter diminishing returns.

There are a number of ways that these benefits of devolution might be expected to appear. An important implication of decomposability is that every management problem in the system does not have to be coordinated or solved simultaneously. Thus, the transaction costs of management are reduced when there are relatively independent lower-level management units, corresponding with subsystems, simply because information about activities whose impacts are contained within any given locality does not have to be passed up and down the organizational hierarchy and does not need to be the subject of explicit coordination. Management decisions can be partitioned into an efficient grouping of spatially nested, hierarchical subsystems in which the scale at which feedback occurs is mirrored as much as possible in the scale of decision authority or, in the language of economics, in which the costs and benefits of decisions can be nearly internalized. These efficiencies of multiscale organization reduce the transactions costs of governance and make it possible to do more for the same expenditure of resources.

The partial isolation of local subsystems means that natural or man-made disasters are also partially isolated, and the tendency for local shocks to propagate through the system is dampened. This provides resilience to the wider system, but it also means that the potential costs of management experiments are greatly reduced. Near-decomposability means that it is possible to find local ecological circumstances that are more homogeneous, more self-contained, more easily monitored and, therefore, more amenable to good experimental design than would be possible in a broadscale, heterogeneous arrangement. Good experimental designs are more likely to be credible to resource users and, for that reason, more likely to be undertaken. Looked at from another angle, in multiscale systems with many local management units the probability of making mistakes, as well as the costs of those mistakes is much less than might be expected in a centralized regime, and for this reason experimentation is more likely to occur.

One of the most significant limits to the efficiencies that can be obtained from multiscale organization arises from the fact that ecological organization rarely fits the rigid hierarchy of human organizational charts. In this sense, ecological systems are open and leaky, and their successful management requires expensive communication and coordination across organizations. In this regard, Vincent Ostrom (1991) writes about the tendency of relatively independent organizational entities to create polycentric networks; that is, networks that communicate up and down the organizational hierarchy, as they are supposed to according to most organizational charts, and across scale and outside the hierarchy, in a way that does not conform to the organizational charts. The most 
notable aspect of polycentric networks, at least from the efficiency perspective, is the self-interested motivation that defines their structure. Organizations initiate communication outside the hierarchy of which they are a part in order to protect and further their own interests. The selectivity of these incentives generates a self-organizing process that restricts information flows to a subject matter and volume that is deemed economical by the affected organizations (Levitt and March 1988).

This is important in fisheries management because fish and other organisms tend to cross any fixed human boundary. For a local organization, this openness means a loss of control. Organizations elsewhere can affect its well being, usually adversely through intercept fisheries, etc. Therefore, to protect its own interests, a local organization can be expected to identify and to address the significant ecological events that cross the boundaries of its jurisdiction. This is immediately obvious at the scale of nation states, but exactly the same organizational incentives arise at local scales (Young 2002). Without some sort of local control, the ruling incentives for participants are those of roving banditry; with local organization, on the other hand, each locality has a compelling need to pay attention to what its neighbors are doing to the fish. Consequently, the result of this concern is that the flow of information in a multiscale and cross-scale system becomes self-organizing, efficient, and strongly oriented toward resolving the ecological externalities that arise because of necessarily imperfect human boundaries. Additionally, when management communicates at several different scales, and at many different locations at the same scale, its ability to understand how local phenomena affect or propagate to broader scales, and how broader scale events impact more local scales is greatly enhanced. As such, local organization and polycentric networks complement one another. They reinforce the institutional circumstances that facilitate strong conservation incentives, and facilitate the allocation of resources for the acquisition of the information necessary to act upon those incentives. Thus, the self-interest of local organizations injects into the system a crossboundary, multi-scale conservation interest that is basically absent in a centralized regime.

Enhanced governance capabilities are another important consequence of multiscale organization. Governance is easier, but certainly not assured of success, among smaller groups of people who are in reasonably frequent contact with one another (Ostrom 1990, Acheson 2003). Repetitive interactions, shared homogeneous circumstances, and the communication advantages of face-to-face contact make it possible to engage in deliberative processes, to develop assurances about others' intentions and, consequently, to develop rules that might not otherwise be feasible. It may be possible to agree to particular gear restrictions or times and places of fishing or other circumstances of harvest that, in an arm's-length, impersonal, slow-moving, centralized environment would not be enforceable or even realistic to consider. This gives management a much broader scope for experimentation, and is another reason to expect a faster rate of learning, adaptation, and presumably, better conservation.

A closely related and not often mentioned benefit of multiscale organization is that careful partitioning of system-wide decision making reduces the number of people who have to be engaged at any particular scale. This tends to create some of the advantages of face-to-face, repetitive contact. Multiscale and cross-scale communications constrain internal group dynamics at all scales so that they are less prone to the impasses and excesses that seem to arise frequently in small groups, the darker side of face-to-face, repetitive contact. This occurs because the imperfect decomposability of the system continuously exposes small groups, at all scales, to other elements in the system. This increases the likelihood that alternative knowledge and/or policies will become known and, thereby, increases the chances for continued learning and adaptation.

In short, from a social and management perspective the importance of the place-based, coevolved adaptations of marine organisms and populations is that these adaptations create a degree of local ecosystem coherence. This makes it possible to simplify the complexity of the ecosystem through the place-based, multiscale organization of management. A multiscale social/organizational arrangement that is congruent to the natural system in this way increases our ability to obtain feedback from the system and reduces the transactions costs of management. This tends to relax the constraints on the practical application of our scientific conceptions and, thereby, expands the set of economically feasible management policies. This puts us in a better position to address the many drivers of a complex system and, most important, 
to experiment, learn, and adapt to the ocean environment.

\section{Appropriate Incentives}

Nevertheless, these benefits of organizational congruency are significantly limited in systems in which fine-scale phenomena are important to system functioning. At this scale, what counts is the decision making of the individual, not the collective decisions of a group. In a relatively simple system, e.g., as in a conventional single species conception, the fine-scale limitations on organizational effectiveness do not appear to be significant. Rights constructed around a single driver such as fishing mortality can be enforced relatively easily, and their costs would not be expected to be a significant barrier to effective management. However, if one adopts a view of ocean systems that places an emphasis on multiple drivers, many operating at fine scales, one's view of the importance of fine-scale adaptations is increased, as is one's view of the costs of not accomplishing that adaptation. With finescale complexity, as organization devolves to a finer scale, boundaries become more numerous, and the frequency of ecological externalities, i.e., effects that extend beyond the scope of the local decision maker, increases. Individuals and groups are presented with more and more opportunities for gain at the expense of their neighbors. This raises the costs of monitoring and enforcement and tends to offset the benefits of better feedback. Failure to solve this problem at local scales can lead to the loss of local system components and accumulate to failure of the system as a whole.

Developing appropriate incentives is not, of course, a problem that is unique to fisheries. It is, in a sense, a principal problem of human governance. The question is how we might arrange our own governance so that individuals and groups have the liberty to use their own intelligence for their own benefit without, at the same time, being able to pass costs onto or acquire uncompensated benefits from others. The solution to the problem is in the institutions we use to govern our individual and collective behavior (McCay and Acheson 1987, Ostrom 1990). Institutions are the collection of coevolved and/or designed norms, customs, rules, and laws that give us relatively secure expectations about one another's behavior and, for that reason, allow us to engage in collective action. Institutions limit self-interested behavior, but also open the door to new and different opportunities that otherwise might not be present. If we create rules prohibiting trespass, we deny ourselves the opportunity to go onto one another's land, e.g., for example, to gather the fruits of natural production, but by so agreeing we create the far more beneficial, long-term opportunities that arise from the possibility of cultivation that is secure from theft. Hence, when we develop effective rules that prohibit trespass, our self-interested incentives shift away from the pursuit of activities that are individually beneficial, but likely to have a collectively detrimental effect, toward the pursuit of activities that are individually and collectively beneficial.

The overfishing problem is the same kind of problem. It involves the establishment of rules that restrain individual fishing activities and, thereby, close off many short-term opportunities. If those restraining rules are effective they create greater, but different, fishing opportunities that better serve the long-term interests of both individuals and society. For rules to be effective in a complex, changing environment, however, it is extremely important that the terms of individual rights are designed in a way that is matched with the spatial and functional dimensions of the individual components of the natural system. Consider a simple terrestrial example in which individual rights holders are given exclusive access to a piece of land. Such rights create circumstances in which the rights holders might learn how to adjust their own behavior in a way that enhances the natural production or, even more, so that they might learn how to deliberately cultivate crops or animals. The eventual outcome will depend almost entirely upon the knowledge of the rights holders and their ability to use that knowledge to influence production. If the life history and relevant ecological dependencies of the organisms of interest to the rights holders are nicely contained within the boundaries of their land, their ability to capture feedback about the effects of their actions and, consequently, to learn is greatly enhanced. To the extent that this is not the case, much of the potential value of their right is out of their control, and their future is dependent to a certain extent upon the actions of others.

In these cases and in the absence of agreements concerning mutual action or restraint, each right holder must take advantage of opportunities that shift their own costs of production onto their neighbor and/or steal the benefits of their neighbors' efforts. For example, in many terrestrial systems, 
the tendency to create small-scale property rights without broader scale considerations has led to unintended, broadscale environmental problems. Curtin (2002) cites the transformation of large areas of grazing lands in the southwestern part of the United States to unusable brush, because given the limitations of their property right and desire to maximize income, individual ranchers, or the Bureau of Land Management acting for them, suppressed the large-scale fires necessary for the maintenance of a grass dominated, grazing friendly regime. Many similar agricultural examples quickly come to mind, e.g., the U.S. dust bowl in the 1930s, the desertification of the Sahel, salinization of irrigated agricultural lands, the runoff of nutrients that leads to the eutrophication of lakes, and so on.

In almost all these cases, rights were not wellmatched with the relevant ecological scales, and this encouraged fine-scale behavior that led to the erosion of the system upon which the rights were predicated. It is probably fair to assume that the designers of the rights system did not set out to deliberately create the circumstances that would destroy the value of those rights. Their design was most likely a reflection of their mental model of the ecological system they were in. However, with hindsight it is clear that they created rights regimes that encouraged behavior that, over time, either destroyed or significantly reduced the value of those rights. Even when these effects were recognized, the regimes were often unable to respond effectively, because the people holding those rights were so heavily invested in the physical and human capital appropriate to the expectations that accompanied those rights at the time of their establishment and not to the newly recognized eroded state of their system (see Diamond 2004).

Fisheries also are subject to an inseparable connection between our mental model of the system and the expectations people form about appropriate investments in knowledge and capital. For example, given the species-specific, broadscale mental model of system function that characterizes conventional management, a single species regime that creates individual rights to a share in an overall quota, e.g., an individual transferable quota, would be expected to generate incentives consistent with the long-term sustainability of the resource. Scott (1993) makes an interesting and important argument to the effect that individual fishing rights can be expected to promote a strong interest in the private and collective acquisition of knowledge for maximizing the benefits stream associated with the right. For example, quota shares generate these kinds of incentives. Holders of quota shares should be, and generally are, interested in good enforcement, good population assessments, and better understanding the behavior of the species to which their rights are connected. In most instances, these collective interests are strong enough to call forth self-taxation schemes, collaborative science efforts, and a variety of other collective actions that are almost completely absent in open access regimes. The short run efficiency effects that arise in these circumstances are clearly demonstrable.

The other side of that same coin is that any set of rights also creates strong incentives to withhold information or to resist the public acquisition of certain kinds of knowledge, also for the purpose of maximizing the benefits stream available to the rights holder. Fishermen are not likely to reveal where they made that big haul yesterday, that sweet little hole where they have been bringing in a steady catch for the last couple of weeks, the by-catch they incur, or the habitat for some other fishery that they happen to be destroying while making a good catch. Open access rights might be expected to lead to a strong disposition to oppose the development of almost any knowledge other than what is necessary for the immediate private exploitation of the resource, simply because any addition to publicly held knowledge has a strong likelihood of leading to competitive or regulatory restrictions on the income stream derived from that right. Similarly, the holder of a species-specific license or a quota share is not likely to be interested in the public acquisition of knowledge that his or her behavior causes damage to another fishery or to the system as a whole and, for this reason, is likely to withhold that kind of knowledge from the public domain and/ or oppose its public acquisition.

Oliver Williamson (1985) uses the phrase "information impactedness" to characterize the incentives people acquire in these situations; like a sore tooth, information just does not want to come out. Consequently, because fishing rights bias the acquisition of knowledge, it is important that they be carefully matched to the natural system so that they encourage the private provision of the ecological knowledge necessary for sustainability, or in different language, so that we can avoid being locked in to local optima that are inconsistent with sustainability (Frenken et al. 1999). Fishermen, but also administrative and scientific bureaucracies, 
invest heavily on the basis of the expectations created by the rights regime in which they work and, for that reason alone, their private, administrative, and scientific interests are usually threatened by change (Finlayson 1994). They become strongly interested in the persistence of the current regime whether it is collectively beneficial or not. For example, a rights regime tuned to a broadscale conception of management generally creates strong incentives for large, mobile boats that can search efficiently for a school or aggregation of fish and harvest them with a minimum of cost and time. Ownership and investment patterns, product markets, processing, labor markets, administrative organization, and scientific knowledge all adapt to the geographic and technological scale of harvesting that flows out of the interaction of individual rights, management scale, and the attributes of the resource. A fundamental management change that requires, for example, rights adapted to a fine-scale ecological approach is likely to redefine efficiency and business success in terms of different fishing strategies, different technology, and different market arrangements, all of which are likely to threaten current business and bureaucratic strategies, investments, and skills.

For these reasons, the design of access rights that are consistent with sustainability is critically dependent on our mental model of ecosystem structure and process. That model molds our expectations about what kind of knowledge we need for sustainability and the kind of rights regimes appropriate to the acquisition of that knowledge. Complexity means we will always be faced with imperfect knowledge about the functioning of the ecosystem and our affect upon that functioning; for that reason the design of rights appropriate to this kind of system must avoid, as much as possible, the tendency toward path-dependent lock-in and must emphasize incentives for the private and public acquisition of broad knowledge about the system.

In this regard, it is interesting that the de facto rights that fishermen create for themselves in near openaccess, multispecies conditions bear a closer resemblance to intellectual property rights than they do to the kind of agricultural land rights that are the implicit model in most of the fishery and common property literature (Gatewood 1984, Wilson 1990). The reason these de facto rights are configured in this way is due to a fisherman's inability to produce specific biological outcomes. As a result, what pays off for each individual is the continuous acquisition of information about the current configuration of the resource. This knowledge is his greatest asset, and it is the reason why fishermen tend to be so secretive about where they fish.

However, good fishermen are also good cooperators. A coordinated search process, or simply the reciprocal exchange of information about the results of individual search, greatly expands a fisherman's knowledge of current circumstances and, at the same time, makes substantial contributions to the historical database he carries in his head and uses to interpret current information. Unfortunately for fishermen, it is difficult for even a small group to maintain sharing arrangements for any appreciable period. This is because the proprietary value of information about current fishing is so high, and its exchange with, or "sale" to other fishermen who are not part of the arrangement, is so easy. This makes it difficult to monitor, verify, and enforce the terms of its sharing. Even if the terms of the arrangement are not actually broken, fishermen's inability to effectively monitor one another and, because of the complexity of the system, the necessarily ambiguous terms specifying the sharing contract make it difficult to maintain an atmosphere of trust. As a result, cooperative sharing arrangements break down frequently.

In spite of this, these kinds of arrangements are interesting because they mobilize valuable, but select private knowledge in a way that results in a collective benefit, i.e., within the sharing group. As such, these arrangements provide a tentative model for a rights system, capable of addressing the knowledge requirements of complex fisheries. The most problematic aspect of such a model concerns the individual cost-benefit calculation that each fishermen is forced to confront when deciding whether to contribute private knowledge to the public pool. Put simply, the problem is that any information a fisherman contributes to the public pool stands a good chance of being translated into new, restrictive rules and/or might put his competitors in a better situation and, therefore, reduce his fishing opportunities. The only thing that will lead to a decision to provide private knowledge is an expectation that those possible costs will lead to different and better fishing opportunities that are of net benefit to him as an individual. In the instance of coordinated or reciprocal search the payoffs from shared information are relatively short term and usually easy to correlate with the receipt of shared information. The information a fisherman might 
provide for regulatory purposes, on the other hand, will have a much longer term and much less certain payout. To take a simple example, if a fisherman were to report large aggregations of mixed juvenile and adult fish, it is possible that a governing body will choose to close fishing on that aggregation. In the short run, a well-enforced closure will lead to a loss of catch and income for the reporting fisherman. However, in the long run, at least as long as it takes the juveniles to reach harvestable size, the fisherman, but only as a member of a group, might possibly encounter much better fishing opportunities. Whether his expectation of future benefit is positive depends critically on the fisherman's sense of the likely biological outcome and on whether he is likely to be in a position to capture any of the benefits of that outcome. Both a fishermans' expectations about biological outcomes and about his future share of that outcome are a function of the governance regime.

The way in which governance affects those expectations is the subject of a large literature on common resources (McCay and Acheson 1987, Pinkerton 1989, Ostrom 1990, Hanna 1997). Among other things, that literature has come to emphasize the importance of small groups and communities because in these circumstances, rule making is easier, compliance higher, and enforcement cheaper. The "collective feedback/ complex systems" problem outlined here does not contradict any of the lessons of that literature. In fact, a complex environment magnifies the importance of these governance capabilities. This is because the cost-benefit calculus that individuals have to consider in a complex environment is not straightforward. The "looseness" of natural regulatory processes in this kind of system means that any connection between fishing restraints and biological outcomes is likely to be ambiguous, and the longer the term and the more species-specific the objective of the restraint, the less certain the outcome. As a result, the compelling causal relationships that are often theorized as the basis for self-interested restraint tend to be absent or at least tenuous and always changing.

The role of governance in this kind of situation is not simply a matter of setting and bringing about compliance with rules that have well-known outcomes. There is a critical prior step, i.e., the creation of conditions that elicit the private provision of public knowledge about the environment and the human players in that environment. This kind of information is necessary for reasonable collective decisions in a complex environment and is something that the governance regime, especially impersonal arms-length governance, cannot compel. Consequently, because the individual cost of those private contributions is always positive, what is important to the fisherman and to the collective is not so much the police power of the state, but the expectation that the terms under which information is provided will lead to beneficial results.

Conventional management does its best to ignore the way that complexity affects rule making and favors, instead, a mental model in which the ecosystem and individual populations operate in some sort of simple, clockwork mechanism with clear, if stochastic, causality and predictability. Rights designed using this mental model produce behavior consistent with that perspective, but not necessarily consistent with sustainability. Fishermen, of course, pursue their self-interest as best they can whatever rights they are dealt. For example, when rights bind fishermen into species-specific fisheries, those rights expose them to the difficulties of forecasting, i.e., controlling outcomes at the species level. This does not mean that they cannot develop expectations of private gain, but it does mean that those expectations will lead to fishing strategies and to private investments in physical and human capital that reflect the kinds of biological outcomes that can be produced or forecasted given the species-specific terms of the right. In particular, given this particular mismatch of rights and the environment, one would expect a rational maximizing fisherman to have a strong preference for knowledge and activities that emphasize relatively predictable, short-term outcomes, e.g. maximizing his yield from a recruited year class. These activities are not necessarily consistent with system sustainability, and, even with an excellent governance process, may do nothing to prevent, and may perversely encourage, the erosion of ecosystem structure and function. Similarly, economizing public officials who hold the same temporal perspective can be expected to have strong preferences toward policies that respond to these private incentives. The point for economists is that the discount individuals apply to the future value of the resource is a function of their rights, and that single species rights create strong biases in favor of high discount rates.

On the other hand, rights that are congruent with a subsystem, e.g., a particular area of the ocean, will 
generate different feedback and self-interested patterns of learning. They shift the basis for individual expectations toward whatever natural regularities are consistent with the functioning of the subsystem, not only a particular species. If fishermens' numbers are limited, such rights give them the flexibility to adapt to the compensating variation among populations; this shifts their individual forecasting horizon to a much longer temporal scale than is likely to be the case for any individual population. It tends to internalize ecological connections, and for these reasons, in the presence of good governance, such rights can be expected to generate strong incentives for the private acquisition and provision to the public of knowledge about the long-term dynamics of the entire subsystem. As noted earlier, private rights of this sort will generate, through the political process, strong incentives for the administrative and scientific acquisition of complementary, system relevant public knowledge. In effect, a systembased rights regime can be expected to generate strong incentives for the acquisition of both private and public knowledge that is consistent with the sustainability of the system and, importantly, lower the rate at which the future is discounted. Such rights, by themselves, are inadequate for a solution to the problem of the ocean commons. Good governance is still required to stitch ecologically congruent rights and organization into a workable collective solution.

\section{CONCLUSION}

The purpose of this paper is to explore the nature of feedback arising from social-ecological linkages in complex adaptive fisheries systems. When compared with conventional fisheries management, this perspective leads to different interpretations of the impact of human activity on these systems and, therefore, to different ideas about how human social behavior might be better matched to ecological structure and function. In particular, from this perspective, the management structures, and individual fishing rights that are the intellectual children of conventional broadscale, single-species theories of fish populations fail to match human activity to ecological structure and function. They tend to encourage regulatory responses that optimize short-term, forecastable, bioeconomic objectives; this leads to the unintended erosion of ecosystem structure and function and, consequently, diminishes system sustainability.
1. The organization of complex ocean ecosystems is best decomposed into, or conceptualized as, a set of spatially nested, nearly independent subsystems.

2. Our practical ability to obtain good feedback about the behavior of ocean systems is limited principally by the collective transaction costs we incur acquiring knowledge about its complexity and coordinating our approach to its use.

3. A multiscale organization, congruent with the spatial structure of the ecosystem, reduces the transaction costs of management and facilitates our collective ability to experiment, learn about, and adapt to both local and broad circumstances in a timely and appropriate way.

4. The ability to forecast future states in ocean systems is generally a function of the biological mass of the entity under consideration, i.e., short for small organisms and small populations and longer for large organisms, large populations, and the system itself.

5. Individuals' and organizations' self-interests leads them to preferentially direct their acquisition of knowledge of the natural world, their adoption of new technology, and their capital investments toward those activities whose outcomes they can forecast and, given their rights, control.

6. Individual rights have to be congruent with ecological structure and function, i.e., system-based rather than species-based, in order to avoid "roving bandit" incentives and assure that individuals' self-interested actions are consistent with the long-term temporal scale required for sustainability, and

7. The ambiguity of cause-and-effect in a complex natural system places a high premium on the continuous acquisition of 
system relevant information and, because of that, on relatively personal forms of governance that are able to generate the assurances necessary to bring forth the private provision of that information.

From a practical perspective, improved feedback for the purpose of better science and management will require multiscale governance that starts at a local scale, in which the most effective boundaries of localities are defined by the spatial organization of the ecosystem. It will require, further, polycentric organization that is able to establish the efficient flows of information and countervailing interests needed to compensate for the always-imperfect ability to match human organization with the complexity of ecological organization. This organization will need to be buttressed by individual rights to fish that are congruent with the spatial and temporal structure of the ecosystem, i.e., areabased, multispecies or subsystem-wide, fishing rules and gear designed to accommodate the finescale behavior of individual organisms and populations. Finally, both organization and rights have to be embedded within a system of relatively personal governance that is able to develop the assurances necessary to bring the fine-scale knowledge of fishermen into play in the management of the resource.

Responses to this article can be read online at: http://www.ecologyandsociety.org/voll1/iss1/art9/responses/

\section{Acknowledgments:}

In the course of the various drafts of this paper, I have received helpful and challenging comments from a number of people. They include two anonymous reviewers, Spencer Apollonio, Dana Rice, Ted Ames, Heather Deese, Yong Chen, Carl Wilson, Jim McCleave, Elinor Ostrom, Les Kaufman, Heather Leslie and Charles Curtin. I also want to thank my students in the dual degree program in marine science who put up with many of these ideas when they were not well formed and the many Maine fishermen and members of the Downeast Initiative who patiently (sometimes) discuss these matters. Support for work leading to this article comes from Maine Sea Grant, the National Science Foundation Program Biocomplexity in the Environment, OCE-0410439, and the
National Center for Ecological Analysis and Synthesis, Working Group on Ocean EcosystemBased Management: The Role of Zoning.

\section{LITERATURE CITED}

Acheson, J. M. 2003. Capturing the commons. University Press of New England. Hanover, Maine, USA.

Ames, E. P. 1997. Cod and haddock spawning grounds of the Gulf of Maine from Grand Manan to Ipswich Bay. Pages 55-64 in The implications of localized fishery stocks. Natural Resource, Agriculture, and Engineering Service, Ithaca, New York, USA.

Ames, E. P. 2004. Atlantic cod stock structure in the Gulf of Maine. Fisheries 29:1.

Apollonio, S. 2002. Hierarchical perspectives on marine complexities. Columbia University Press, New York, New York, USA.

Arrow, K. 1974. The limits of organization. Norton, New York, New York, USA.

Beverton, R. 1998. Fish, fact, and fantasy: a long view. Reviews in Fish Biology and Fisheries 8:229-249.

Conover, D. O. 2000. Darwinian fishery science. Marine Ecology Progress Series. 208:303-307.

Cooper, A., and M. Mangel. 1999. The dangers of ignoring metapopulation structure for the conservation of salmonids. Fisheries Bulletin 97:213-226.

Costanza, R., R.Andrade, P.Ataunes, M. van den Belt, D. Boersma, D. Boesch, R. Catarino, S. Hanna, K. Limburg, B. Low, M. Molitor, J. Pereira, S. Rayner, R. Santos, J. Wilson, and M. Young. 1998. Principles of sustainable governance of the oceans. Science 281:198-199.

Cowen, R. K., M. Kamazima, S. Sponaugle, C. Paris, and D. Olson. 2000. Connectivity of marine populations: open or closed? Science 287:857-859. 
Curtin, C., N. Sayre, and B. Lane. 2002. Transformations of the Chihuahuan Borderlands: grazing, fragmentation, and biodiversity conservation in desert grasslands. Environmental Science and Policy 5:55-68.

Degnbol, P. 2001. Science and the user perspectivethe scale gap and the need for shared indicators. People and the Sea Inaugural Conference, (Amsterdam, 2001). Center for Maritime Research (MARE), Amsterdam, The Netherlands. [online] URL: www.ifm.dk/reports/60.pdf.

Diamond, J. 2005. Collapse. Viking, New York, New York, USA.

Elmqvist, T., C. Folke, M. Nostrum, G. Peterson, J. Bengtsson, B. Walker, and J. Norberg. 2003. Response diversity, ecosystem change, and resilience. Frontiers in Ecology and the Environment 1(9):488-494.

Finlayson, A. C. 1994. Fishing for truth: a sociological analysis of northern cod stock assessments from 1997 to 1990. Social and Economic Studies Volume 2. Institute of Social and Economic Research, Memorial University of Newfoundland, St. Johns, Newfoundland, Canada.

Flake, G. 1998. The computational beauty of nature: computer explorations of fractals, chaos, complex systems, and adaptation. MIT Press, Cambridge, Massachusetts, USA.

Fogarty, M. J., and S. A. Murawski. 1998. Largescale disturbance and the structure of marine systems: fishery impacts on Georges Bank. Ecological Applications, Supplement 8(1)S6-S22.

Folke, C., F. Berkes, and J. Colding. 1998. Ecological practices and social mechanisms for building resilience and sustainability. Pages 414-436 in F. Berkes and C. Folke, editors. Linking social and ecological systems.

Cambridge University Press, Cambridge, UK.

Frank, K., K. Drinkwater, and F. Page. 1994. Possible causes of recent trends and fluctuations in Scotian Shelf/Gulf of Maine cod stocks. ICES Journal of Marine Science 198:110-120.

Frank, K., B. Petrie, J. Choi, and W. Leggett. 2005. Trophic cascades in a formerly coddominated ecosystem. Science 308:1621-23.
Frenken, K., L. Marengo, and M. Valente. 1999. Interdependencies, nearly-decomposability, and adaptation. Computable and Experimental Economics Laboratory (CEEL) Technical Report 3. [online] URL:

www-ceel.gelso.unitn.it/papers/papero99 03.pdf.

Friedmann, J. 1987. Planning in the public domain: from knowledge to action. Princeton University Press, Princeton, New Jersey, USA.

Gatewood, J. 1984. Cooperation, competition, and synergy: information sharing groups among southeast Alaska salmon seiners. American Ethnologist 11(2):350-370.

Graham, J. J. 1982. Production of larval herring, Clupea harengus, along the Maine Coast, 1964-78. Journal of Northwest Atlantic Fisheries Science 3:63-85.

Green, J. M., and J. S. Wroblewski. 2001. Movement patterns of Atlantic cod in Gilbert Bay, Labrador: evidence for bay residency and spawning site fidelity. Journal of the Marine Biological Association of the United Kingdom 80:1077-1075.

Guichard, F., S. Levin, A. Hastings, and D. Siegel. 2004. Toward a dynamic metacommunity approach to marine reserve theory. BioScience 54(11):1003.

Gunderson, L. 1999. Resilience, flexibility, and adaptive management-antidotes for spurious certitude? Conservation Ecology 3(1):7.

Hanna, S. 1997. The new frontier of American fisheries governance. Ecological Economics 20:221-233.

Hayek, F.A. 1945. The use of knowledge in society. American Economic Review 35:519-530.

Hixon, M., S. Pacala, and S. Sandin. 2002. Population regulation: historical context and contemporary challenges of open vs. closed systems. Ecology 83(6):1490-1508.

Holland, J. 1998. Emergence. Perseus Books, Cambridge, UK.

Holling, C. S., and L. H. Gunderson. 2002. Resilience and adaptive cycles. Pages 25-62 in L. H. Gunderson and C. S. Holling, editors. Panarchy: 
understanding transformations in natural and human systems. Island Press, Washington, D.C., USA.

Hughes, T., D. Bellwood, C. Folke, R. Steneck, and J. Wilson. 2005. New paradigms for supporting the resilience of marine ecosystems. Trends in Ecology and Evolution 20:7.

Hutchings, J.A. 2000. Numerical assessment in the front seat: ecology and evolution in the back seat: time to change drivers in fisheries and aquatic sciences? Marine Ecology Progress Series 208:299-303.

Hutchings, J. A., and R. A. Myers. 1995. The biological collapse of Atlantic cod off Newfoundland and Labrador. Pages 37-94 in R. Arnason and L. Felt, editors. The North Atlantic fisheries: successes, failures, and challenges. Island Institute Studies, Charlottetown, Prince Edward Island. Canada.

Jackson, J. B. C., M. X. Kirby, W. H. Berger, K. A. Bjorndal, L. W. Botsford, B. J. Bourque, R. H. Bradbury, R. Cooke, J. Erlandson, J. A. Estes, T. P. Hughes, S. Kidwell, C. B. Lange, H. S. Lenihan, J. M. Pandolfi, C. H. Peterson, R. S. Steneck, M. J. Tegner, and R. R. Warner. 2001. Historical overfishing and the recent collapse of coastal ecosystems. Science 293:629-638.

Jones, K. 2005. Monitoring, assessment, and management of the green sea urchin (Strongylocentrotus droebachiensis fishery in Maine. Thesis, University of Maine, School of Marine Sciences, Maine, USA.

Kritzer, J. and P Sale. 2004. Metapopulation ecology in the sea: from Levin's model to marine ecology and fisheries science. Fish and Fisheries 5:131-140.

Levin, S. 1999. Fragile dominion. Perseus Books, Cambridge, UK.

Levitt, B., and J. G. March. 1988. Organizational learning. Annual Review of Sociology 14:319-340.

Low, B., E. Ostrom, C. Simon, and J. Wilson. 2002. Redundancy in social and ecological systems. Pages 83-114 in F. Berkes, J. Colding, and C. Folke, editors. Navigating nature's dynamics: building resilience for adaptive capacity in social-ecological systems. Cambridge University Press, Cambridge,
UK.

McCay, B. J., and J. Acheson. 1987. The question of the commons: the culture and ecology of communal resources. University of Arizona Press, Tucson, Arizona, USA.

McLeod, K. L., J. Lubchenco, S. R. Palumbi, and A. A. Rosenberg. 2005. Scientific consensus statement on marine ecosystem-based management. Communication Partnership for Science and the Sea. [online] URL:

www.compassonline.org/?q=EBM.

Myers, R. A., and B. Worm. 2003. Rapid worldwide depletion of predatory fish communities. Nature 423:280-283.

National Research Council (NRC). 1999a. Sharing the fish: toward a national policy on individual fishing quotas. Committee to Review Individual Fishing Quotas. Commission on Geosciences, Environment, and Resources. National Academy Press, Washington, D.C., USA.

National Research Council (NRC). 1999b. Sustaining marine fisheries. Committee on Ecosystem Management for Sustainable Marine Fisheries, Ocean Studies Board. Commission on Geosciences, Environment, and Resources. National Academy Press, Washington, D.C., USA.

Neal, B. 2001. Eastern Gulf of Maine Atlantic herring spawning area survey. Island Institute, Rockland, Maine, USA.

Olson, M. 2000. Power and prosperity: outgrowing communist and capitalist dictatorships. Basic Books, New York, New York, USA.

O'Neill, R. V., D. L. DeAngelis, J. B. Waide, and T. F. H. Allen. 1986. A hierarchical concept of ecosystems. Princeton University Press, Princeton, New Jersey, USA.

Ostrom. E. 1990. Governing the commons: the evolution of institutions for collective action. Cambridge University Press, New York, New York, USA.

Ostrom, V. 1991. Polycentricity: the structural basis of self-governing systems. Pages 223-148 in V. Ostrom, editor. The meaning of American federalism: constituting a self-governing society. 
ICS Press, San Francisco, California, USA.

Pauly, D., V. Christensen, J. Dalsgaard, R. Froese, and F. C. Torres, Jr. 1998. Fishing down marine food webs. Science 279:860-863.

Pauly, D., and J. Maclean. 2003. In a perfect ocean: fisheries and ecosystem in the North Atlantic. Island Press, Washington, D.C., USA.

Perkins, H. C., S. B. Chenoweth, and R. W. Langton. 1997. The Gulf of Maine Atlantic cod complex, patterns of distribution, and movement of the Sheepscot Bay substock. Bulletin of the National Research Institute of Aquaculture, Supplement 3:101-107.

Pew Oceans Commission. 2003. America's living oceans: charting a course for sea change. Pew Oceans Commission, Arlington, Virginia, USA.

Pinkerton, E. 1989. Co-operative management of local fisheries: new directions for improved management and community development. University of British Columbia Press, Vancouver, British Columbia, Canada.

Pitcher T. 2001. Fisheries managed to rebuild ecosystems: reconstructing the past to salvage the future. Ecological Applications 11(2):601-617.

Rietkerk, M., S. Dekker, P. C. de Ruiter, and J. van de Koppel. 2004. Self-organized patchiness and catastrophic shifts in ecosystems. Science 305:1927-1929.

Robichaud, D., and G. Rose. 2004. Migratory behavior and range in Atlantic cod: inference from a century of tagging. Fish and Fisheries 5:185-214.

Scott, A. 1993. Obstacles to fishery selfgovernment. Marine Resource Economics 8:187-199.

Scott, J. 1998. Seeing like a state: how certain schemes to improve the human condition have failed. Yale University Press, New Haven, Connecticut, USA.

Scheffer, M., S. Carpenter, J. A. Foley, C. Folkes, B. Walker. 2001. Catastrophic shifts in ecosystems. Nature 413:591-596.

Simon, H. 1996. The sciences of the artificial. Third edition. MIT Press, Cambridge, Massachusetts,
USA.

Sinclair, M., J. O'Boyle, D. L. Burke, and G. Peacock. 1997. Why do some fisheries survive and others collapse? Pages 23-35. in Developing and sustaining world fisheries resources: the state of science and management. Proceedings of the Second World Fisheries Congress (Melbourne, 1996). CSIRO, Collingwood, Australia.

Smedbol, R. K., and R. Stephenson. 2001. The importance of managing within-species diversity in cod and herring fisheries of the north-western Atlantic. Journal of Fish Biology, Supplement A:109-128.

Steneck, R. S. 1997. The importance of managing within-species diversity in cod and herring fisheries of the north-western Atlantic. Pages 151-165 in Proceedings of the Gulf of Maine Ecosystem Dynamics Scientific Symposium and Workshop (Hanover, 1997). Regional Association for Research in the Gulf of Maine (RARGOM) Report 91-1, Hanover, New Hampshire, USA.

Steneck, R. S. 2001. Functional groups. Pages 121-139 in S. Levin, editor. Encyclopedia of biodiversity, Volume 1. Academic Press, New York, New York, USA.

Steneck, R. S., J. Vavrinec, and A. V. Leland. 2004. Accelerating trophic-level dysfunction in kelp forest ecosystems of the western North Atlantic. Ecosystems 7:323-332.

Stephenson, R. L. 1998. Consideration of localized stocks in management: a case statement and a case study. Pages 160-178 in I. Hunt von Herbing, I. Kornfield, M. Tupper, and J. Wilson., editors. The implications of localized fishery stocks. Natural Resource, Agriculture, and Engineering Service, New York, New York, USA.

Taggart, C.T., D. E. Ruzzante, and D. Cook. 1998. Localised stocks of cod (Gadus morhua L.) in the northwest Atlantic: the genetic evidence and otherwise. Pages 65-90 in I. Hunt von Herbing, I. Kornfield, M. Tupper, and J. Wilson, editors. The implications of localized fishery stocks. Northeast Regional Agricultural Engineering Service, New York, New York, USA.

United States Commission on Ocean Policy (USCOP). 2004. An ocean blueprint for the 21st 
century. Final Report of the U.S. Commission on Ocean Policy to the President and Congress, Washington, DC., USA.

Vavrinec, J. 2003. Resilience of green sea urchin (Strongylocentrotus droebachiensis) populations following fishing mortality: marine protected areas, larval ecology and post-settlement survival. Dissertation. University of Maine, School of Marine Sciences, Maine, USA.

Walters, C. 2000. Natural selection for predation avoidance tactics: implications for marine population and community dynamics. Marine Ecology Progress Series. 208:309-313

Williamson, O. 1985. The economic institutions of capitalism. The Free Press, New York, New York, USA.

Wilson, J. A. 1990. Fishing for knowledge. Land Economics 66(1):12-29.

Wilson, J. A. 2002. Scientific uncertainty, complex systems, and the design of common pool institutions. Pages 327-360 in P. Stern, E. Ostrom, T. Dietz, and N. Dolsak, editors. The drama of the commons. National Research Council, Committee on Human Dimensions of Global Climate Change. National Academies Press, Washington, D.C., USA.

Wilson, J. A., E. Ostrom, B. Low, and R. Costanza. 2000. Scale misperceptions and the spatial dynamics of a social-ecological system. Ecological Economics 31:243-57.

Wilson, J. A., and R. Townsend. 1986. An economic view of the tragedy of the commons: from privatization to switching. Pages $311-326$ in $\mathrm{J}$. Acheson and B. McKay, editors. The question of the commons. University of Arizona Press, Tucson, Arizona, USA.

Wroblewski, J. S. 1998. Substocks of northern cod and localized fisheries in Trinity Bay, eastern Newfoundland and in Gilbert Bay, southern Labrador. Pages 104-116 in I. Hunt von Herbing, I. Kornfield, M. Tupper, and J. Wilson, editors. The implications of localized fishery stocks. Natural Resource, Agriculture, and Engineering Service. New York, New York, USA.

Young, O. 2002. Institutional interplay: the environmental consequence of cross-scale interactions. Pages 327-360 in P. Stern, E. Ostrom, T. Dietz, and N. Dolsak, editors. The drama of the commons. National Research Council, Committee on Human Dimensions of Global Climate Change, National Academies Press, Washington, D.C., USA. 